\title{
Physiological and pharmacological inductors of HSP70 enhance the anti-oxidative defense mechanisms of the liver and pancreas in diabetic rats
}

\begin{tabular}{|r|l|}
\hline Journal: & Canadian Journal of Physiology and Pharmacology \\
\hline Manuscript ID & cjpp-2017-0394.R1 \\
\hline Manuscript Type: & Article \\
\hline Date Submitted by the Author: & 07-Aug-2017 \\
\hline Complete List of Authors: & $\begin{array}{l}\text { Dimitrovska, Maja; Institute of Biology Faculty of Natural Sciences and } \\
\text { Mathematics University "St Cyrilus and Methodius", Department of } \\
\text { Experimental Physiology and Biochemistry } \\
\text { Dervisevik, Mirsada; Institute of Biology Faculty of Natural Sciences and } \\
\text { Mathematics University "St Cyrilus and Methodius", Department of } \\
\text { Experimental Physiology and Biochemistry } \\
\text { Cipanovska, Natasa; Institute of Biology Faculty of Natural Sciences and } \\
\text { Mathematics University "St Cyrilus and Methodius", Department of } \\
\text { Experimental Physiology and Biochemistry } \\
\text { Gerazova, Katerina; Department of Experimental Physiology and } \\
\text { Biochemistry, Institute of Biology, Faculty of Natural Sciences and } \\
\text { Mathematics, University "St Cyril and Methodius", Skopje, R. Macedonia } \\
\text { Dinevska - Kjovkarovska, Suzana; Institute of Biology Faculty of Natural } \\
\text { Sciences and Mathematics University "St Cyrilus and Methodius", } \\
\text { Department of Experimental Physiology and Biochemistry } \\
\text { Miova, Biljana; Faculty of Natural Sceinces, Department of Experimental } \\
\text { Physiology and Biochemistry, Institute of Biology }\end{array}$ \\
\hline Is the invited manuscript for & Konsideration in a Special \\
Issue?: & N/A \\
\hline Keyword: & $\begin{array}{l}\text { heat preconditioning, aspirin, experimental diabetes, HSP70, oxidative } \\
\text { status }\end{array}$ \\
\hline & \\
\hline & \\
\hline
\end{tabular}

\section{SCHOLARONE" \\ Manuscripts}


Physiological and pharmacological inductors of HSP70 enhance the anti-oxidative defense mechanisms of the liver and pancreas in diabetic rats

\section{Maja Dimitrovska, Mirsada Dervisevik, Natasa Cipanovska, Katerina Gerazova, Suzana Dinevska- Kjovkarovska and Biljana Miova*}

Department of Experimental Physiology and Biochemistry, Institute of Biology, Faculty of Natural Sciences and Mathematics, University "St Cyril and Methodius", Skopje, R. Macedonia

Maja Dimitrovska, MSci

majabt2003@yahoo.com

Mirsada Dervisevik, MSci

mirsadadervisevik@yahoo.com

Natasa Cipanovska, MSci

natasacipan@hotmail.com

Katerina Gerazova

kgerazova@gmail.com

Prof. Suzana Dinevska - Kjovkarovska, PhD

suzanadk@pmf.ukim.mk

*Corresponding author:

Prof. Biljana Miova, PhD

Department of Experimental Physiology and Biochemistry, Institute of Biology

Faculty of Natural Sciences and Mathematics, University "St Cyril and Methodius",

Skopje, R. Macedonia 
Arhimedova 3, 1000 Skopje, R. Macedonia

Phone: + 38923249604

Fax. +38923228141

E-mail: bmiova@pmf.ukim.mk; bmiova@yahoo.com

We confirm that all authors have approved the final version of the paper.

We confirm that there is no conflict of interest between authors.

The research was performed at the Department of Experimental Physiology and Biochemistry, Institute of Biology, Faculty of Natural Sciences and Mathematics, University "St Cyril and Methodius", Skopje, R. Macedonia

This research did not receive any specific grant from funding agencies in the public, commercial or non-profit sectors. 


\begin{abstract}
Heat preconditioning (HP) is a powerful adaptive and protective phenomenon and the heat stress proteins (HSPs) it produces are an important determinant for the development of diabetic complications. Aspirin has been reported to modulate heat shock response in different organisms through increased induction of HSPs and is also known to exert anti-oxidative and radical scavenging effects in diabetes. We estimated the effect of physiological [heat stress (HS), 45min / $41 \pm 0.5^{\circ} \mathrm{C}$ )] and pharmacological (aspirin treatment) induction of HSP70 on several parameters of oxidative state in the pancreas and liver of diabetic rats. Diabetes increased HSP70 level and decreased PARP, glutathione (GSH) and glutathione peroxidase (GPx) activities in pancreas. In liver there was reduction of HSP70 level, GSH concentration and CAT activity, while GPx and GR activity were enhanced. Heat preconditioning of diabetic rats caused an additional increase of HSP70, GSH and antioxidant enzymes in both organs. Pre-treatment of HP-diabetic animals with aspirin led to an additional increase of PARP and HSP70. In conclusion, both HP and aspirin, as physiological and pharmacological inductors of HSP70, respectively, enhance the anti-oxidative defense mechanisms of the liver and pancreas in diabetic rats.
\end{abstract}

Key words: heat preconditioning, aspirin, experimental diabetes, HSP70, oxidative status. 


\section{Introduction}

Diabetes mellitus (DM) and insulin resistance are inflammatory conditions that result in modification of cellular proteins, oxidative stress and a reduced cellular defense system (Cossins and Bowler 1987; Atalay and Laaksonen 2002; Shan et al. 2003), conditions which are strongly correlated with heat shock protein (HSPs) disorders (Bruce et al. 2003) and indicate altered heat shock response (HSR) (Hooper 2007). A remarkably low expression of HSP72 in skeletal muscle of T2DM patients with impaired glucose tolerance was observed for the first time by Kurucz et al. (2002). Low levels of HSPs contribute to an impaired stress response, protein glycation, oxidation and aggregation, free radical formation and inflammation and may be a clue to the etiology of the disease itself (Hooper et al. 2014).

The most favorable condition to increase the production of HSPs is exposure of the organism of the cells to an acute heat stress (HS) (Parsell and Lindquist 1993). Furthermore, organism / cells previously exposed to sub-lethal HS display greater resistance to the effects of higher intensity stress, including hypoxia, ischemia/reperfusion (Joyeux et al. 1999) or a strong cytotoxic agent, such as the diabetogenic agent streptozotocin (STZ) (Panchnadikar and Bhonde 2003; Najemnikova et al. 2007), a phenomenon known as a heat preconditioning (HP). In particular, enhanced cell survival in heat-exposed organisms has been linked to the expression of HSPs as specific molecular chaperones and housekeeping molecules (Zhu et al. 2009). There is some evidence pointing to the beneficial effect of HP in diabetes (Hooper 1999; Bathaie et al. 2010). Heat therapy, via hot tub immersion, improves diabetic glycemic control and diabetic neuropathy in patients with type 2 diabetes (Hooper 1999) and significantly improves lipid profile, antioxidant capacity, insulin secretion and serum HSP70 level in diabetic rats (Bathaie et 
al. 2010). In rodents, heat treatment $\left(41-41.5^{\circ} \mathrm{C}\right)$ and overexpression of HSP72 have been shown to prevent high-fat diet-induced insulin resistance (Chung et al. 2008; Gupte et al. 2009).

In addition to physiological induction by heat-preconditioning, there are also pharmacologically methods of inducing HSP production; among them, non-steroidal antiinflammatory drugs (NSAIDs), such as sodium salicylate, aspirin and indomethacin, have been reported to modulate HSR in different organisms (Winegarden et al. 1996; Fawcett et al. 1997) and improve thermal response during hyperthermia and other toxic conditions through increased induction of HSPs (Batulan et al. 2005). Aspirin, an anti-inflammatory drug (non-specific cyclooxygenase (COX) inhibitor), is known to exert other pharmacological effects, including stimulation of insulin secretion and hypoglycaemia, as well as anti-oxidative effects, radical scavenging, diminishing of endogenous oxidant stress and activation of antioxidant defenses in a condition of diabetes (Zarich 2009; Caballero et al. 2000; Prasad and Lee 2011; Ayyadevara et al. 2013; ).

Diabetes mellitus induced experimentally by streptozotocin (STZ) causes $\beta$-cell death by alkylation of DNA (Elsner et al. 2000) and activation of the DNA-damaging enzyme poly(ADP) ribose polymerase (PARP) in pancreatic $\beta$-cells (de Murcia et al. 1997; Wang et al. 1997), which is a main reason for the increase of ROS, RNS, NO and protein carbonylation in different organs (pancreas, liver, kidney and brain) of diabetic rats (Nourooz-Zadeh et al. 1997; Raza et al. 2011; Raza and John 2012). Among these organs, the pancreas has a relatively low expression of antioxidant enzymes (Zhang et al. 1995; Lenzen and Drinkgern 1996), while the liver has the highest antioxidant capacity when compared with other tissues (Navarro-Arévalo and Sánchezdel-Pino 1998) in diabetic rats. 
Taking into consideration the above, we aimed to investigate: 1.the effects of physiological induction of HSPs by heat preconditioning in diabetic animals; and 2. the pharmacological induction of HSPs by aspirin and its possible metabolic modifications in HP-diabetic animals. To do this, we evaluated changes in HSP70 levels, PARP activity and the antioxidative defense system in the liver and pancreas in STZ - diabetic rats.

\section{Material and methods}

\section{Animals and tissue procedures}

This experimental study was performed with adult (3 - 4 months old) male Wistar rats $(n=80)$ with a weight of $250-300 \mathrm{~g}$, which were housed under a 12-hour light regime (6 a.m. -6 p.m. light) and fed laboratory chow and water ad libitum. All experimental animals were anaesthetized with Na-thiopental narcosis $(45 \mathrm{mg} / \mathrm{kg}$ ) and sacrificed using a standard laparothomic procedure, always at the same time of day (9-10 a.m.). The isolated pancreas and liver were washed with cold saline solution and immersed in liquid nitrogen. The tissues were kept at $-80^{\circ} \mathrm{C}$ until analysis and were converted into tissue powder before analysis (at liquid $\mathrm{N}_{2}-$ temperature). The tissue powder was homogenized with an ultrasonic homogenizer (Cole-Parmer Instrument - 4710) in several 7-10 sec. cycles. The whole procedure was performed at $0-4^{\circ} \mathrm{C}$ (on ice). All procedures followed the Canadian Council on Animal Care.

\section{Study design and treatments}

The animals were divided into two general groups: healthy animals and diabetic ones. The first group was divided into three subgroups: control animals (C), heat-preconditioned control animals (HC) and heat-preconditioned control animals pretreated with ASA (AHC). The 
diabetic group was divided into six subgroups: control diabetic groups (D2 and D14 - sacrificed 2 or 14 days after STZ-administration, respectively); heat-preconditioned diabetic groups (HD2 and HD14 - sacrificed 2 or 14 days after STZ-administration, respectively) and heatpreconditioned diabetic groups, pretreated with ASA (AHD2 and AHD14 - sacrificed 2 or 14 days after STZ-administration, respectively).

Heat preconditioning (HP) was carried out by placing animals in special temperaturecontrolled chambers $\left(45 \mathrm{~min}\right.$ at $\left.41 \pm 0.5^{\circ} \mathrm{C}\right)$, followed by $24 \mathrm{~h}$ recovery at room temperature $(20 \pm$ $\left.2^{\circ} \mathrm{C}\right)$

The duration of diabetes in our experiment was defined by the following criteria: minimum period for manifestation of the effect of administrated STZ (48h) and optimal period for the development of diabetic complications (14 days); abundant HSP70 protein level in the first $24-48 \mathrm{~h}$ after the single HS, and further decrement after the $72 \mathrm{~h}$ after the HS [both in cells (Miova et al. 2015) and in rats (Horowitz 2003)]. Experimental diabetes mellitus was induced by a single intraperitoneal injection of streptozotocin (STZ, $55 \mathrm{mg} / \mathrm{kg}$ body weight) and was freshly dissolved in $0.1 \mathrm{M}$ citrate buffer, $\mathrm{pH}=4.5$. All animals with clear diabetic symptoms (fasting glycemia levels higher than $15 \mathrm{mmol} / \mathrm{L}$ ) 24-48 hours after the induction of the experimental diabetes were included in the experiment.

Aspirin (ASA - acetylsalicylic acid, Sigma-Aldrich) was freshly dissolved in water and administrated to the animals in a concentration of $100 \mathrm{mg} / \mathrm{kg} \mathrm{b.w}$. Subsequently, sodium carbonate was slowly added until the ASA crystals had dissolved (the $\mathrm{pH}$ of the solution remained just below 7.0 (Kelton et al. 1978) and was administrated intraperitoneally in a 0.5-mL volume (Fawcett et al. 1997; Locke and Atance 2000), one hour before exposure to heat stress.

Table 1. 


\section{Biochemical analyses}

The protein level of HSP70 was determined with an appropriate commercial kit (HSP70 EIA, Enzo), and PARP activity was measured with a colorimetric commercial kit (TREVIGEN). GSH concentration was determined with a commercial kit (Glutathione Assay Kit, SigmaAldrich), while the enzyme activity of glutathione peroxidase (GPx) and glutathione reductase (GR) was determined by a modification of the commercial kits (Sigma-Aldrich). Catalase activity was assessed following Aebi's method (Aebi 1984). Analyses to determine GPx, GR, total GSH, HSP70, PARP were performed with a microplate reader (BioRad), while the activity of catalase and total protein was measured with a UV-spectrophotometer (Cary 50, Varian).

\section{Statistics}

Results are presented as means \pm SD. Statistical differences between groups were examined using one-way ANOVA with a Neuman-Keuls post-hoc test. A probability level of $\mathrm{p}<0.05$ was considered to be significant. The overall statistical data processing was performed using the statistical program Statgraph for Windows.

\section{Results}

\section{Rectal temperature (effects of HP, ASA and ASA+HP)}

Our measurements showed a significant increase of rectal temperature of about $3.7^{\circ} \mathrm{C}$ in HP-animals, which returned to basal values after $24 \mathrm{~h}$ recovery at room temperature (Table 2 ). Aspirin (ASA) treatment alone produced a rise of rectal temperature of about $1{ }^{\circ} \mathrm{C}$ one hour after the treatment, while a combination of $\mathrm{ASA}+\mathrm{HP}$ led to an additional increase of rectal 
temperature (total increment of about $4.4^{\circ} \mathrm{C}$, Table 3). Finally, when animals had recovered for $24 \mathrm{~h}$ at room temperature, their rectal temperature was found to return to normal.

\section{Pancreas}

Figure 1 shows the results obtained for HSP70 protein level (Fig. 1A), PARP activity (Fig. 1B), total gluthatione (GSH) concentration (Fig. 1C) and gluthatione peroxidase (GPx) activity (Fig. 1D) in the pancreas of our rats.

Twenty-four hours after HS there was a significant increase in the level of pancreatic HSP70 level and GPx activity and a significant decrease in PARP activity and total GSH concentration compared to control animals (C:HC). Pretreatment of HP-control animals with ASA (HC:AHC) resulted in an additional increase of HSP70 $(\mathrm{p}<0.050)$, a significant increase of PARP activity and GSH concentration and a significant decrease of GPx activity compared to heat-preconditioned control animals (HC).

Our results show there was a significant increase in pancreatic HSP70 level and significant decreases in PARP activity, total GSH concentration and GPx activity, both 2d- and 14d after STZ administration (C:D2, C:D14). Heat preconditioning of diabetic animals (D2:HD2, D14:HD14) led to a significant increase in HSP70 level in 2d-diabetic animals and a significant decrease in HSP70 level in 14d-diabetic animals. Heat preconditioning led to an increase of GSH concentration only in 14d-diabetic animals and an increase of GPx activity regardless of the duration of diabetes. Moreover, pretreatment of HP-diabetic animals with ASA (HD2:AHD2, HD14: AHD14) resulted in a further increase in HSP70 level (only in 2d-diabetic animals), a significant increase in PARP activity, and non-significant changes in GSH concentration and GPx activity. 
Finally, time-dependent changes were manifested with respect to HSP70 level and GSH concentration - significantly lower HSP70 and significantly higher GSH in 14d-diabetic animals versus 2d-diabetic animals - regardless of whether or not there was aspirin treatment (HD2:HD14 and AHD2:AHD14, p<0.050).

\section{Figure 1.}

\section{Liver}

Figure 2 shows the results obtained for the parameters studied in the liver: HSP70 protein level (Fig. 2A), total GSH concentration (Fig. 2B), GPx activity (Fig. 2C), GR activity (Fig. 2D) and CAT activity (Fig. 2E).

We observed that HP led to a significant 10-fold increase in hepatic HSP70 protein level, a significant increase of GPx and GR activity, and a significant reduction in GSH concentration compared to control animals (C:HC). Pretreatment with ASA caused an additional increase in HSP70 level $(p<0.050)$ and an almost total reversal of antioxidative parameters in HP-animals.

Our results showed that STZ-diabetes (C:D2, C:D14) led to a significant reduction in hepatic HSP70, total GSH and CAT, and a significant increase of GPx and GR in the liver. Heat preconditioning of diabetic rats resulted in a significant increase in HSP70 level and total GSH concentration, as well as an increase in GR and CAT activity compared to diabetic rats (D2:HD2, D14:HD14). Treatment with ASA led to an additional increase of HSP70 in both 2dand 14d-diabetic animals, an additional increase of CAT activity in 2d-diabetic animals, and a decrease of GR-activity in both 2d- and 14d-diabetic animals and GPx activity in 2d-diabetic animals (HD2:AHD2, HD14: AHD14) with respect to HP-diabetic animals. 
In diabetic animals time-dependent changes were manifested only with respect to HSP70 level - significantly lower HSP70 in 14d-diabetic animals versus 2d-diabetic animals, regardless of whether or not there was aspirin treatment (HD2:HD14 and AHD2: AHD14, p<0.05).

Figure 2.

\section{Discussion}

\section{Heat stress / heat preconditioning}

The first evident manifestation of acute HS $\left(45 \mathrm{~min}, 41 \pm 0.5^{\circ} \mathrm{C}\right)$ that we observed was a significant increase of rectal temperature of approximately $3.7^{\circ} \mathrm{C}$, which returned to control values after $24 \mathrm{~h}$ recovery at room temperature. This elevated rectal temperature in intact animals led to a significant increase of HSP70 protein levels in both organs: up to 3- and 10-fold in the pancreas and the liver, respectively. A number of studies suggest that HSP70 has a protective function in the prevention of cellular damage in thermal injury (Horowitz 2002) and that its synthesis is a crucial part of the whole physiological response to the stressor (Feder and Hofmann 1999).

The glutathione (GSH) metabolic network also exhibits profound disruption in response to heat stress, since free radicals and other ROS are neutralized by GSH in redox regulation cycles (Ippolito et al. 2014). The pancreas is particularly vulnerable to the harmful effects of ROS due to its lower expression of antioxidant enzymes compared to other tissues (Zhang et al. 1995; Lenzen and Drinkgern 1996). We observed that 24h after HS there was a significant reduction of total GSH concentration in the pancreas with respect to control animals. By contrast, the liver is the organ with the highest antioxidant capacity (Navarro-Arévalo and Sánchez-del-Pino 1998). 
The decreased concentration of GSH and elevated activity of GPx, GR and CAT observed in our rats clearly manifest an activated anti-oxidative defense mechanism of the liver.

Increased ROS may also lead to apoptosis, DNA damage and disruption of the metabolism (Trachootham et al. 2008). Our research reveals a significant decrease of PARP activity in the pancreas $24 \mathrm{~h}$ after exposure to HS. Interestingly, with its catalytic activity, PARP can also affect the transcription of specific genes, including genes for HSP70 (Tulin and Spradling 2003; Juet al. 2006; Krishnakumar and Kraus 2010). Little is known of how PARP activates transcription of HSP70 after HS, but research by Petesch and Lis (2012) in Drosophila melanogaster indicates that PARP is associated with the 5' end of HSP70 and that its enzymatic activity is rapidly induced by HS, which causes PARP to redistribute throughout HSP70 loci. It is possible that the reduced activity of PARP as a result of HS involves binding of strongly elevated HSP to PARP or to the DNA molecule (Bellmann et al. 1995).

\section{Experimental diabetes}

PAPR is a constitutively expressed nuclear enzyme which can be activated by damaged DNA (Kim et al. 2004; Pinnola et al. 2007), and a single application of STZ leads to expression of cleaved PARP in the first 6 hours in rats and for a shorter period in isolated cells ( $3 \mathrm{~h}$ after STZ application) ( $\mathrm{Ku}$ et al. 2012). In our experiments, the reduced activity of PARP might have accounted for the decreased PARP activity in a time-delay course (2d- and 14d- after STZ administration). Pancreatic $\beta$-cells are vulnerable to oxidative stress as they possess reduced antioxidant levels, including glutathione peroxidase (GPx) and catalase (Newsholme et al. 2012). Our results show that the induction of experimental diabetes, regardless of its duration, leads to a significant reduction in GSH concentration in the pancreas, accompanied by a significant 
decrease in GPx activity. Interestingly, islet cells have been reported to have a disturbed GSH metabolism, with a 10-fold lower GPx activity compared with other cell types (Malaisse et al. 1982). In our experiments, the diabetic livers manifested a significant reduction in GSH levels and a significant increase in GR and GPx activity. Indeed, it is known that GPx gene expression is regulated by the concentration of $\mathrm{H}_{2} \mathrm{O}_{2}$ and other oxidants (Matés et al. 1999), and the increased production of ROS during diabetes can inhibit certain antioxidant enzymes, such as CAT (Sindhu et al. 2004), which we observed in our experiments.

Finally, our results showed tissue-specific regulation and expression of HSP - there was a significant increase of protein levels in the pancreas and a decrease in the liver. Experimental monkeys have manifested a similar response to DM - increased HSP70 protein expression and HSF (heat shock factor) in pancreatic tissue versus a reduction of both parameters in the liver (Kavanagh et al. 2009). Namely, in organs with high secretory capacity, such as the liver and pancreas, HSPs are vital for a normal physiology of the organism (Hooper 2007), and the vulnerability of diabetic animals is due heavily to disturbances of HSPs.

\section{Heat preconditioning of diabetic animals}

The main mechanism of heat preconditioning is based on production of cellular HSPs, which have strong cytoprotective effects and speed up recovery from additional stress. Our results show that HP of diabetic animals causes a significant increase compared to diabetic controls in HSP70 levels in both organs, especially the liver. Heat-stressed diabetic animals show an increased HSP72 and HSP25 content in the heart, kidney, and liver compared to the same tissues from heat-stressed, non-diabetic animals (Najemnikova et al. 2007). Nevertheless, a significantly lower HSP70 expression has been reported in 14d- versus 2d-diabetic animals, 
which is in accordance with other reports showing that HSP72 synthesis flourishes in the first 24-48 following HS and declines later on (Horowitz 2003). In HepG2 cells, abundant level of HSP70 and BCl-2 was observed 24-48h after the single HS, which indicate that HS might be a "physiological conditioner" and might obtain cytoprotection against an additional stress (Miova et al. 2015).

Additionally, we found that HP led to an improvement in the redox potential of the diabetic pancreas and reduced oxidative damage, evident in the increased total GSH level in 14d-diabetic animals, followed by a significant increase in GPx activity.

On the other hand, the liver is organ-guard during thermal stress (Hall et al. 1994; Kregel et al. 1995) and is also sensitive to changes in diabetic conditions. According to Raza and John (2012), STZ treatment of human hepatocellular cells causes cytotoxicity, formation of ROS, and oxidative stress by increasing lipid peroxidation and altering the GSH-dependent antioxidant metabolism. Our results show that HP-diabetic animals have a significantly higher concentration of total GSH and increased GR and CAT activity in the liver compared to normothermic diabetic animals. This is in accordance with Panchnadikar and Bhonde (2003), who reported that thermoresistent cells are generally resistant to environmental stress and death. In the same line, results obtained in HeLa cells have shown that hyperglycaemia and oxidative stress up-regulate HSP60 and HSP70 expression concomitantly to the increase in the intracellular levels of ROS (Hall and Martinus 2013).

\section{Aspirin pretreatment of HP- control and diabetic animals}

We observed that aspirin administration given as a pre-treatment to acute HS enhanced the rise of rectal temperature by about $4.5^{\circ} \mathrm{C}$ in ASA-treated $\mathrm{HP}$-control rats (Table 3). Our 
assumption is that this is a main trigger for additional production of HSP70 in both the liver and pancreas with respect to non-ASA-treated HP-control animals (Fig. 1A and 2A). It is known that aspirin treatment causes a slight rise in body core temperature in rats, even in an absence of heat, but treatment with aspirin prior to HS markedly enhances heat-induced HSP70 levels (Fawcett et al. 1997). Aspirin can also reduce the temperature threshold of the HSR (Koo et al. 2000), acting as a co-inducer of HSP and emphasizing HSP expression (Fawcett et al. 1997). According to our results, increased HSP70 synthesis due to ASA pretreatment was accompanied by a significantly higher PARP activity (about 32.6\%) with respect to non-treated HP- animals, but enzyme activity was still significantly lower than that of control animals. Furthermore, our results demonstrate that ASA pre-treatment reversed both GSH concentration and enzyme activity in the liver and pancreas of HP- control animals to almost control levels.

In HP-diabetic rats, ASA-pretreatment produced an additional increase of HSP70 concentration in both the liver and pancreas, and a significant increase in PARP activity in the pancreas. It is important to note that these changes were evident only in 2 d-diabetic animals, indicating that time-dependent changes in HSP production are related to the duration of the recovery period after the HS. We believe that the increased synthesis and accumulation of HSP70 in the pancreas during ASA pretreatment resulted in a lower reduction of PARP activity in diabetic animals. In terms of oxidative enzymes, ASA pretreatment did not cause significant changes in the pancreas, while in the liver, there was an additional increase of CAT activity and a decrease of GR-activity and GPx activity compared to non-treated HP-diabetic rats. There is evidence that aspirin abolishes accumulation of TBARS in a long term assay and partially reverts catalase activity in diabetic mice (Caballero et al. 2000), and that it has a nitric oxide radicalscavenging potential in atherogenic-diet induced DM in rats (Sethi et al. 2011). Still, more 
analyses should be performed to confirm the antioxidative potential of aspirin during diabetes conditions.

\section{Conclusion}

In conclusion, both HP and aspirin, as physiological and pharmacological inductors of HSP70, respectively, cause alterations in the diabetes-induced oxidative state in the liver and pancreas. We confirm enhanced HSP70 concentrations in the liver and pancreas $24 \mathrm{~h}$ after HS, with an additional increase when there is pretreatment with aspirin. These abundant HSP levels enhance the anti-oxidative defense mechanisms of the liver and pancreas in diabetic rats, suggesting a cross-tolerance between heat preconditioning and STZ-induced diabetes. Moreover, this effect is more expressed in combination with pre-treatment with aspirin, which is known to have a potential HSP-inducing effect.

\section{Acknowledgements}

The authors thank to Dr Nadezda Apostolova for her critical reading and assistance with the preparation of the manuscript and to Brian Normanly for his English language editing of the MS (both of them form Deparment of Pharamacology, Faculty of Medicine, University of Valencia, Valencia, Spain) 


\section{References:}

Aebi H. 1984. Catalase in vitro. Methods Enzymol. 105, 121-126.

Atalay M., Laaksonen D.E. 2002. Diabetes, oxidative stress and physical exercise. J. Sport. Sci. Med. 1(1): $1-14$.

Ayyadevara S., Bharill P., Dandapat A., Hu C., Khaidakov M., Mitra S., Shmookler Reis R.J., Mehta, J.L. 2013. Aspirin inhibits oxidant stress, reduces age-associated functional declines, and extends lifespan of Caenorhabditis elegans. Antioxid. Redox Signal. 18: 481-90.

Bathaie S.Z., Jafarnejad A., Hosseinkhani S., Nakhjavani M. 2010. The effect of hot-tub therapy on serum Hsp70 level and its benefit on diabetic rats: a preliminary report. Int. J. Hyperthermia 26: 577-85.

Batulan Z., Nalbantoglu J., Durham H.D. 2005. Nonsteroidal anti-inflammatory drugs differentially affect the heat shock response in cultured spinal cord cells. Cell Stress Chaperones 10: 185-96.

Bellmann K., Wenz A., Radons J., Burkart V., Kleemann R., Kolb H. 1995. Heat shock induces resistance in rat pancreatic islet cells against nitric oxide, oxygen radicals and streptozotocin toxicity in vitro. J. Clin. Invest. 95: 2840-2845.

Bruce C.R., Carey A.L., Hawley J.A., Febbraio M.A. 2003. Intramuscular heat shock protein 72 and heme oxygenase-1 mRNA are reduced in patients with type 2 diabetes: Evidence that insulin resistance is associated with a disturbed antioxidant defense mechanism. Diabetes 52: 2338- 45.

Caballero F., Gerez E., Batlle A., Vazquez E., 2000. Preventive aspirin treatment of streptozotocin induced diabetes: Blockage of oxidative status and revertion of heme enzymes inhibition. Chem. Biol. Interact. 126: 215-225.

Chung J., Nguyen A.-K.K., Henstridge D.C., Holmes A.G., Chan M.H.S., Mesa J.L., Lancaster G.I., Southgate R.J., Bruce C.R., Duffy S.J., Horvath I., Mestril R., Watt M.J., Hooper P.L., Kingwell B.A., Vigh L., Hevener A., Febbraio M.A. 2008. HSP72 protects against obesity-induced insulin resistance. Proc. Natl. Acad. Sci. U. S. A. 105: 1739-44.

Cossins R., Bowler K. 1987. Temperature biology of animals. Chapman Hall, New York, NY. 
de Murcia J.M., Niedergang C., Trucco C., Ricoul M., Dutrillaux B., Mark M., Oliver F.J., Masson M., Dierich A., LeMeur M., Walztinger C., Chambon P., de Murcia G. 1997. Requirement of poly(ADP-ribose) polymerase in recovery from DNA damage in mice and in cells. Proc. Natl. Acad. Sci. U. S. A. 94: 7303-7.

Elsner M., Guldbakke B., Tiedge M., Munday R., Lenzen S. 2000. Relative importance of transport and alkylation for pancreatic beta-cell toxicity of streptozotocin. Diabetologia 43: 1528-1533.

Fawcett T.W., Xu Q., Holbrook N.J. 1997. Potentiation of heat stress-induced hsp70 expression in vivo by aspirin. Cell Stress Chaperones 2: 104-109.

Feder M.E., Hofmann G.E. 1999. Heat shock proteins, molecular shaperones and the stressresponse Evolutionary and Ecological Physiology. Annu. Rev. Physiol. 61: 243-282.

Gupte A.A., Bomhoff G.L., Swerdlow R.H., Geiger P.C. 2009. Heat treatment improves glucose tolerance and prevents skeletal muscle insulin resistance in rats fed a high-fat diet. Diabetes 58: $567-578$.

Hall D.M., Buettner G.R., Matthes R.D., Gisolfi C.V. 1994. Hyperthermia stimulates nitric oxide formation: electron paramagnetic resonance detection of NO-heme in blood. J. Appl. Physiol. 77: $548-553$.

Hall L. and Martinus R.D. 2013. Hyperglycaemia and oxidative stress upregulate HSP60 and HSP70 expression in HeLa cells. Springer Plus 2: 431

Hooper P.L. 1999. Hot-tub therapy for type 2 diabetes mellitus. N. Engl. J. Med. 341: 924-5.

Hooper P.L. 2007. Insulin Signaling, GSK-3, Heat Shock Proteins and the Natural History of Type 2 Diabetes Mellitus: A Hypothesis. Metab Syndr Relat Disord 5: 220-230.

Hooper P.L., Hooper P.L. 2009. Inflammation, heat shock proteins, and type 2 diabetes. Cell Stress Chaperones 14: 113-5.

Hooper P.L., Balogh G., Rivas E., Kavanagh K., Vigh L. 2014. The importance of the cellular stress response in the pathogenesis and treatment of type 2 diabetes. Cell Stress Chaperones 19, 447-64. 
Horowitz M. 2003. Matching the heart to heat-induced circulatory load: heat-acclimatory responses. News Physiol. Sci. 18: 215-21.

Horowitz M. 2002. From molecular and cellular to integrative heat defense during exposure to chronic heat, in: Comparative Biochemistry and Physiology - A Molecular and Integrative Physiology. 131(3): 475-483.

Ippolito D.L., Lewis J.A., Yu C., Leon L.R., Stallings J.D. 2014. Alteration in circulating metabolites during and after heat stress in the conscious rat: potential biomarkers of exposure and organ-specific injury. BMC Physiol. 14: 1-17.

Joyeux M., Faure P., Godin-Ribuot D., Halimi S., Patel A., Yellon D.M., Demenge P., Ribuot C. 1999. Heat stress fails to protect myocardium of streptozotocin-induced diabetic rats against infarction. Cardiovasc. Res. 43: 939-946.

Ju B.G., Lunyak V.V, Perissi V., Garcia-Bassets I., Rose D.W., Glass C.K., Rosenfeld M.G. 2006. A topoisomerase II beta-mediated dsDNA break required for regulated transcription. Science 312: $1798-802$.

Kavanagh K., Zhang L., Wagner J.D. 2009. Tissue-specific regulation and expression of heat shock proteins in type 2 diabetic monkeys. Cell Stress Chaperones 14: 291-9.

Kelton J.G., Hirsh J., Carter C.J., Buchanan M.R. 1978. Thrombogenic effect of high-dose aspirin in rabbits. Relationship to inhibition of vessel wall synthesis of prostaglandin I2-like activity. J. Clin. Invest. 62: 892-895.

Kim M.Y., Mauro S., Gévry N., Lis J.T., Kraus W.L. 2004. NAD+-dependent modulation of chromatin structure and transcription by nucleosome binding properties of PARP-1. Cell 119: 803-814.

Koo H.N., Oh S.Y., Kang K.I., Moon D.Y., Kim H. Do, Kang H.S. 2000. Modulation of HSP70 and HSP90 Expression by Sodium Salicylate and Aspirin in Fish Cell Line CHSE-214: Biochemistry. Zoolog. Sci. 17: 1275-1282.

Kregel K.C., Moseley P.L., Skidmore R., Gutierrez J.A., Guerriero Jr. V. 1995. HSP70 accumulation in tissues of heat-stressed rats is blunted with advancing age. J Appl Physiol 79: 1673-1678. 
Krishnakumar R., Kraus W.L. 2010. The PARP Side of the Nucleus: Molecular Actions, Physiological Outcomes and Clinical Targets. Mol. Cell., 39 (1): 8-24

Ku C.R., Lee H.J., Kim S.K., Lee E.Y., Lee M.-K., Lee E.J. 2012. Resveratrol prevents streptozotocininduced diabetes by inhibiting the apoptosis of pancreatic $\beta$-cell and the cleavage of poly (ADPribose) polymerase. Endocr. J. 59: 103-9.

Kurucz I., Morva A., Vaag A., Eriksson K., Huang X., Groop L., Koranyi L. 2002. Decreased expression of heat shock protein 72 in skeletal muscle of patients with type 2 diabetes correlates with insulin resistance. Diabetes. 51 (4): 1102-9.

Lenzen S., Drinkgern J. 1996. Low antioxidant enzyme gene expression in pancreatic islets compared with various other mouse tissues. Free Radic. Biol. Med. 20: 463-6.

Locke M. and Atance J. 2000. The myocardial heat shock response following sodium salicylate treatment. Cell Stress Chaperones. 5(4): 359-368

Malaisse W.J., Malaisse-Lagae F., Sener, Pipeleers D.G., 1982. Determinants of the selective toxicity of alloxan to the pancreatic $\beta$ cell. Proc. Natl. Acad. Sci. USA. 79: 927-30.

Matés J.M., Pérez-Gómez C., Núñez de Castro I. 1999. Antioxidant enzymes and human diseases. Clin. Biochem. 32: 595-603.

Miova B., Dinevska-Kjovkarovska S., Esplugues J.V., Apostolova N., 2015. Heat Stress Induces Extended Plateau of Hsp70 Accumulation - A Possible Cytoprotection Mechanism in Hepatic Cells. J. Cell. Biochem. 116: 2365-2374.

Najemnikova E., Rodgers C.D., Locke M. 2007. Altered heat stress response following streptozotocininduced diabetes. Cell Stress Chaperones 12: 342-352.

Navarro-Arévalo Sánchez-del-Pino, M.J. 1998. Age and exercise-related changes in lipid peroxidation and superoxide dismutase activity in liver and soleus muscle tissues of rats. Mech. Ageing Dev. 104: $91-102$. 
Newsholme P., Rebelato E., Abdulkader F., Krause M., Carpinelli A., Curi R. 2012. Reactive oxygen and nitrogen species generation, antioxidant defenses, and $\beta$-cell function: a critical role for amino acids. J Endocrinol 214: 11-20.

Nourooz-Zadeh J., Rahimi A., Tajaddini-Sarmadi J., Tritschler H., Rosen P., Halliwell B., Betteridge D.J. 1997. Relationships between plasma measures of oxidative stress and metabolic control in NIDDM. Diabetologia 40: 647-653.

Panchnadikar A., Bhonde R. 2003. Can stress provide protection to pancreatic $\beta$-cells and prevent diabetes? Med. Hypotheses. 60(3): 356-9.

Parsell D., Lindquist S. 1993. The function of heat-shock proteins in stress tolerance: degradation and reactivation of damaged proteins. Annu. Rev. Genet. 27: 437-496.

Petesch S.J., Lis J.T. 2012. Overcoming the nucleosome barrier during transcript elongation. Trends Genet. 28 (6): 285-94

Pinnola A., Naumova N., Shah M., Tulin A.V. 2007. Nucleosomal core histones mediate dynamic regulation of poly(ADP-ribose) polymerase 1 protein binding to chromatin and induction of its enzymatic activity. J. Biol. Chem. 282: 32511-32519.

Prasad K., Lee P. 2011. Journal of Cardiovascular Pharmacology and Suppression of Oxidative Stress as a Mechanism of Reduction of Hypercholesterolemic Atherosclerosis by Aspirin. Production 8: 6169.

Raza H., John A., 2012. Streptozotocin-induced cytotoxicity, oxidative stress and mitochondrial dysfunction in human hepatoma HepG2 cells. Int. J. Mol. Sci. 13: 5751-5767.

Sethi A., Parmar H.S., Kumar A. 2011. The effect of aspirin on atherogenic diet-induced diabetes mellitus. Basic Clin. Pharmacol. Toxicol. 108: 371-377.

Shan Y.X., Yang T.L., Mestril R., Wang P.H. 2003. Hsp10 and Hsp60 suppress ubiquitination of insulinlike growth factor-1 receptor and augment insulin-like growth factor-1 receptor signaling in cardiac muscle: Implications on decreased myocardial protection in diabetic cardiomyopathy. J. Biol. Chem. 278: 45492-45498. 
Sindhu R.K., Koo J., Roberts C.K., Vaziri N.D. 2004. Dysregulation of Hepatic Superoxide Dismutase, Catalase and Glutathione Peroxidase in Diabetes: Response to Insulin and Antioxidant Therapies. Clin. Exp. Hypertens. 26: 43-53.

Trachootham D., Lu W., Ogasawara M., Nilsa R.-D.V., Huang P. 2008. Redox regulation of cell survival. Antioxid Redox Signal. 10: 1343-1374.

Wang Z.Q., Stingl L., Morrison C., Jantsch M., Los M., Schulze-Osthoff K., Wagner E.F. 1997. PARP is important for genomic stability but dispensable in apoptosis. Genes Dev. 11: 2347-2358.

Winegarden N.A., Wong K.S., Sopta M., Timothy Westwood J. 1996. Sodium salicylate decreases intracellular ATP, induces both heat shock factor binding and chromosomal puffing, but does not induce hsp 70 gene transcription in Drosophila. J. Biol. Chem. 271: 26971-26980.

Zarich S.W. 2009. Antidiabetic agents and cardiovascular risk in type 2 diabetes. Nat. Rev. Endocrinol. 5: $500-506$.

Zhang H., öllinger K., Brunk, U. 1995. Insulinoma cells in culture show pronounced sensitivity to alloxan-induced oxidative stress. Diabetologia, 635-641.

Zhu, Q., Xu, Y.M., Wang, L.F., Zhang, Y., Wang, F., Zhao, J., Jia, L.T., Zhang, W.G., Yang, A.G., 2009. Heat shock protein 70 silencing enhances apoptosis inducing factor-mediated cell death in hepatocellular carcinoma HepG2 cells. Cancer Biol. Ther. 8: 792-798. 
Table 1. Organization of the experimental groups according the treatments timing.

\begin{tabular}{|c|c|c|c|c|c|c|}
\hline Group & $\begin{array}{c}\text { ASA - } \\
\text { treatment }\end{array}$ & Recovery & $\begin{array}{l}\text { Heat stress } \\
\text { (HS) }\end{array}$ & Recovery & $\begin{array}{c}\text { Duration of } \\
\text { diabetes }\end{array}$ & Sacrifice \\
\hline$\overline{\bar{C}}$ & & & & & & Sacrifice \\
\hline $\mathrm{HC}$ & & & $45 \mathrm{~min} / 41 \pm 0.5^{\circ} \mathrm{C}$ & $24 \mathrm{~h} / 20 \pm 2^{\circ} \mathrm{C}$ & & Sacrifice \\
\hline AHC & $\begin{array}{c}\text { ASA } \\
\text { single dose }\end{array}$ & $1 \mathrm{~h} / 20 \pm 2^{\circ} \mathrm{C}$ & $45 \mathrm{~min} / 41 \pm 0.5^{\circ} \mathrm{C}$ & $24 \mathrm{~h} / 20 \pm 2^{\circ} \mathrm{C}$ & & Sacrifice \\
\hline$\overline{\text { D2 }}$ & & & & & $\begin{array}{c}\text { STZ administration } \\
+2 \text { days }\end{array}$ & Sacrifice \\
\hline HD2 & & & $45 \mathrm{~min} / 41 \pm 0.5^{\circ} \mathrm{C}$ & $24 \mathrm{~h} / 20 \pm 2^{\circ} \mathrm{C}$ & $\begin{array}{c}\text { STZ administration } \\
+2 \text { days }\end{array}$ & Sacrifice \\
\hline AHD2 & $\begin{array}{c}\text { ASA } \\
\text { single dose }\end{array}$ & $1 \mathrm{~h} / 20 \pm 2^{\circ} \mathrm{C}$ & $45 \mathrm{~min} / 41 \pm 0.5^{\circ} \mathrm{C}$ & $24 \mathrm{~h} / 20 \pm 2^{\circ} \mathrm{C}$ & $\begin{array}{c}\text { STZ administration } \\
+2 \text { days }\end{array}$ & Sacrifice \\
\hline D14 & & & & & $\begin{array}{c}\text { STZ administration } \\
+14 \text { days }\end{array}$ & Sacrifice \\
\hline HD14 & & & $45 \mathrm{~min} / 41 \pm 0.5^{\circ} \mathrm{C}$ & $24 \mathrm{~h} / 20 \pm 2^{\circ} \mathrm{C}$ & $\begin{array}{c}\text { STZ administration } \\
+14 \text { days }\end{array}$ & Sacrifice \\
\hline AHD14 & $\begin{array}{c}\text { ASA } \\
\text { single dose }\end{array}$ & $1 \mathrm{~h} / 20 \pm 2^{\circ} \mathrm{C}$ & $45 \mathrm{~min} / 41 \pm 0.5^{\circ} \mathrm{C}$ & $24 \mathrm{~h} / 20 \pm 2^{\circ} \mathrm{C}$ & $\begin{array}{c}\text { STZ administration } \\
+14 \text { days }\end{array}$ & Sacrifice \\
\hline
\end{tabular}


Table 2. Rectal temperature in a function of acute heat stress $\left(45 \mathrm{~min} / 41 \pm 0.5^{\circ} \mathrm{C}\right)$. The temperature was measured just after $\left(0^{\prime}\right)$ or $24 \mathrm{~h}$ after the heat stress. The measurement present the average values for all groups of animals (HC, HD2 and HD14) which were exposed to heat stress.

Legend:

C- rectal temperature in control animals;

HS + $0^{\prime}$ - rectal temperature in animals exposed to acute heat stress, just after ( 0 ') the heat stress;

$\mathrm{HS}+24 \mathrm{~h}$ - rectal temperature in animals exposed to acute heat stress, $24 \mathrm{~h}$ after the heat stress.

Significant difference $\mathrm{p}<0,05$ : a- compared to control; b- compared to $\mathrm{HC}\left(0^{\prime}\right)$

\begin{tabular}{|c|c|c|c|}
\hline \multicolumn{4}{|c|}{ Rectal temperature } \\
in a function of acute heat stress $\left(45 \mathrm{~min} / 41 \pm 0.5^{\circ} \mathrm{C}\right)$ \\
\hline & $\mathrm{C}$ & $\mathrm{HS}+0^{\prime}$ & $\mathrm{HS}+24 \mathrm{~h}$ \\
\hline Average \pm SD & $37,0 \pm 0,7$ & $40,7 \pm 0,7^{\mathrm{a}}$ & $36,9 \pm 0,7^{\mathrm{b}}$ \\
\hline
\end{tabular}


Table 3. Rectal temperature in a function of aspirin treatment (100 mg/ kg b.w.) and exposure to acute HS $\left(45 \mathrm{~min} / 41 \pm 0.5^{\circ} \mathrm{C}\right)$. The temperature was measured $1 \mathrm{~h}$ after the aspirin treatment, as well as just after ( $\left.0^{\prime}\right)$ or $24 \mathrm{~h}$ after the HS. The measurement present the average values for all groups of animals (AHC, AHD2 and AHD14) which were pre-treated with aspirin and exposed to HS 1h later.

Legend:

C- RT in control animals;

$\mathrm{ASA}+1 \mathrm{~h}-\mathrm{RT}$ in animals $1 \mathrm{~h}$ after aspirin treatment;

$\mathrm{ASA}+1 \mathrm{~h}+\mathrm{HS}+0$ '- RT in animals pre-treated with aspirin, $1 \mathrm{~h}$ later exposed to HS and recovered 0 ' at room temperature.

$\mathrm{ASA}+1 \mathrm{~h}+\mathrm{HS}+24 \mathrm{~h}-\mathrm{RT}$ in animals pre-treated with aspirin, $1 \mathrm{~h}$ later exposed to $\mathrm{HS}$ and recovered $24 \mathrm{~h}$ at room temperature.

Significant difference $\mathrm{p}<0,05$ : a- compared to control; b- compared to ASA $+1 \mathrm{~h}$; c- compared to ASA $+1 \mathrm{~h}+\mathrm{HS}+0$ '

\begin{tabular}{|l|c|c|c|c|}
\hline \multicolumn{5}{|c|}{ Rectal temperature } \\
in a function of aspirin treatment and acute heat stress $\left(45 \mathrm{~min} / 41 \pm 0.5^{\circ} \mathrm{C}\right)$. \\
\hline & $\mathrm{C}$ & $\mathrm{ASA}+1 \mathrm{~h}$ & ASA $+1 \mathrm{~h}+\mathrm{HS}+0$ & ASA $+1 \mathrm{~h}+\mathrm{HS}+24 \mathrm{~h}$ \\
\hline $\begin{array}{l}\text { Average } \pm \\
\text { SD }\end{array}$ & $36,9 \pm 0,8$ & $37,7 \pm 0,6^{\mathrm{a}}$ & $41,4 \pm 0,9^{\mathrm{b}}$ & $37,1 \pm 0,8^{\mathrm{c}}$ \\
\hline
\end{tabular}




\section{Figure legends:}

Fig. 1.Changes in pancreas of heat-preconditioned intact and diabetic rats treated with aspirin. A. HSP70 level; B. PARP activity; C. Total gluthatione level; D. Gluthatione peroxidase activity.

Legend:

C- Control (intact) animals;

$\mathrm{HC}$-Control animals exposed to $\mathrm{HS}\left(45 \mathrm{~min} / 41 \pm 1^{\circ} \mathrm{C}\right.$ ), allowed to recover $24 \mathrm{~h}$ at room temperature;

AHC - Control animals treated with aspirin (100 mg/kg b.w), 1 h before HS (45 min $\left./ 41 \pm 1^{\circ} \mathrm{C}\right)$, allowed to recover $24 \mathrm{~h}$ at room temperature.

D2, D14 - Diabetic animals (sacrifice 2 or 14 days after STZ-application);

HD2, HD14 - Diabetic animals exposed to HS (45 $\mathrm{min} / 41 \pm 1^{\circ} \mathrm{C}$ ), allowed to recover $24 \mathrm{~h}$ at room temperature before induction of diabetes (sacrifice 2 or 14 days after STZ-application);

AHD2, AHD14 - diabetic animals treated with aspirin (100 mg/kg b.w $), 1 \mathrm{~h}$ before HS $\left(45 \mathrm{~min} / 41 \pm 1^{\circ} \mathrm{C}\right)$, allowed to recover $24 \mathrm{~h}$ at room temperature before induction of diabetes (sacrifice 2 or 14 days after STZ-application).

Significant difference $(\mathrm{p}<0.050)$ :

a - relative to control animals (C:HC, C:D2, C:D14);

b - relative to diabetic animals (D2:HD2, D14:HD14, respectively);

c - relative to control animals exposed to HS (HC:AHC).

d - relative to diabetic animals exposed to HS (HD2:AHD2, HD14:AHD14, respectively).

Fig. 2. Changes in liver of heat -preconditioned intact and diabetic rats treated with aspirin. A. HSP70 level; B. Total gluthatione level; C. Gluthatione peroxidase activity; D. Glutathione reductase activity; E. Catalase activity.

Legend:

C- Control (intact) animals;

$\mathrm{HC}$-Control animals exposed to $\mathrm{HS}\left(45 \mathrm{~min} / 41 \pm 1^{\circ} \mathrm{C}\right)$, allowed to recover $24 \mathrm{~h}$ at room temperature;

AHC - Control animals treated with aspirin (100 mg/kg b.w), $1 \mathrm{~h}$ before HS (45 min $/ 41 \pm 1^{\circ} \mathrm{C}$ ), allowed to recover $24 \mathrm{~h}$ at room temperature.

D2, D14 - Diabetic animals (sacrifice 2 or 14 days after STZ-application);

HD2, HD14 - Diabetic animals exposed to HS (45 $\mathrm{min} / 41 \pm 1^{\circ} \mathrm{C}$ ), allowed to recover $24 \mathrm{~h}$ at room temperature before induction of diabetes (sacrifice 2 or 14 days after STZ-application);

AHD2, AHD14 - diabetic animals treated with aspirin (100 mg/kg b.w ), $1 \mathrm{~h}$ before HS $\left(45 \mathrm{~min} / 41 \pm 1^{\circ} \mathrm{C}\right)$, allowed to recover $24 \mathrm{~h}$ at room temperature before induction of diabetes (sacrifice 2 or 14 days after STZ-application).

Significant difference $(\mathrm{p}<0.050)$ :

a - relative to control animals (C:HC, C:D2, C:D14);

b - relative to diabetic animals (D2:HD2, D14:HD14, respectively);

c - relative to control animals exposed to HS (HC:AHC).

d - relative to diabetic animals exposed to HS (HD2:AHD2, HD14:AHD14, respectively). 

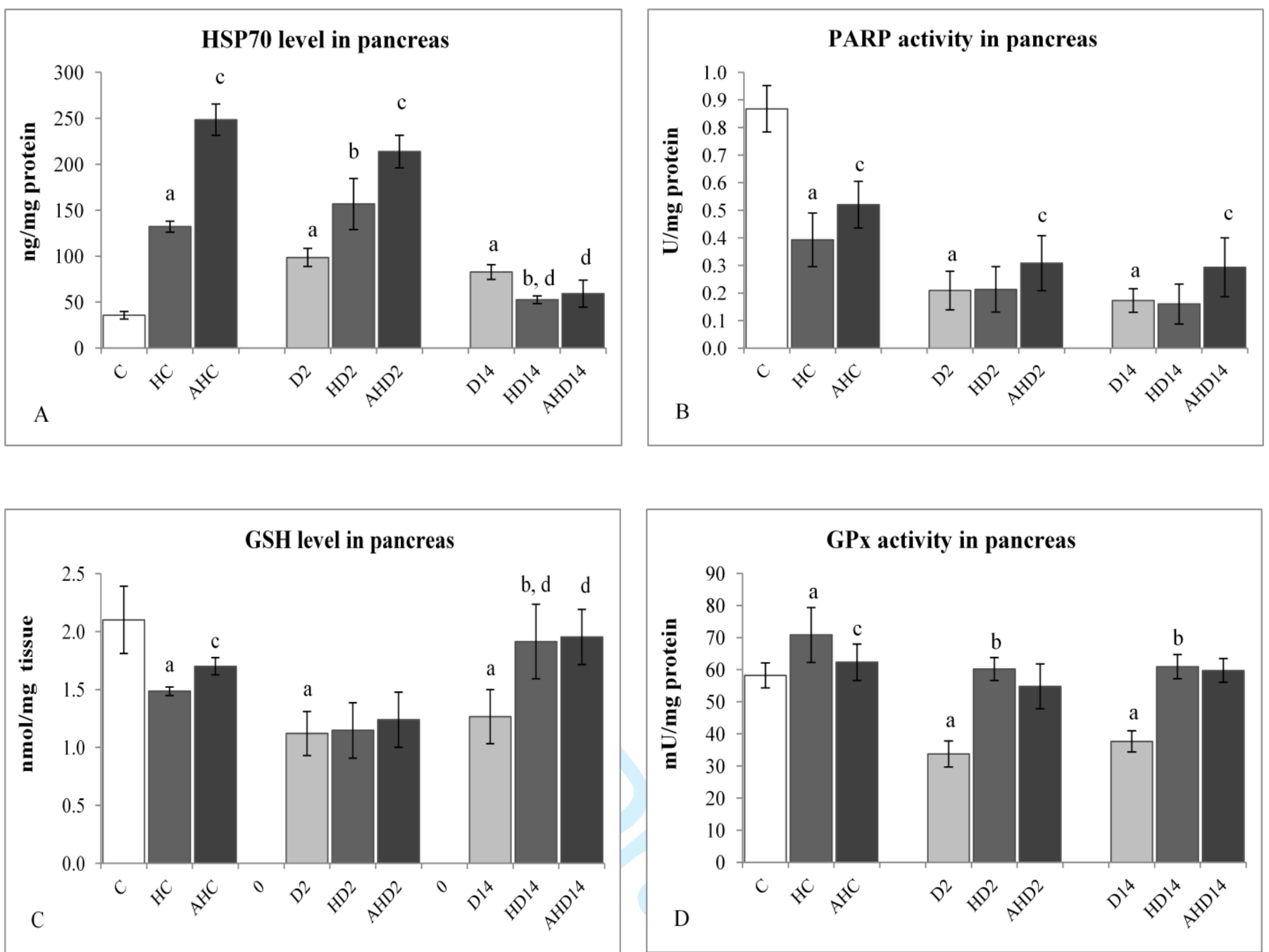

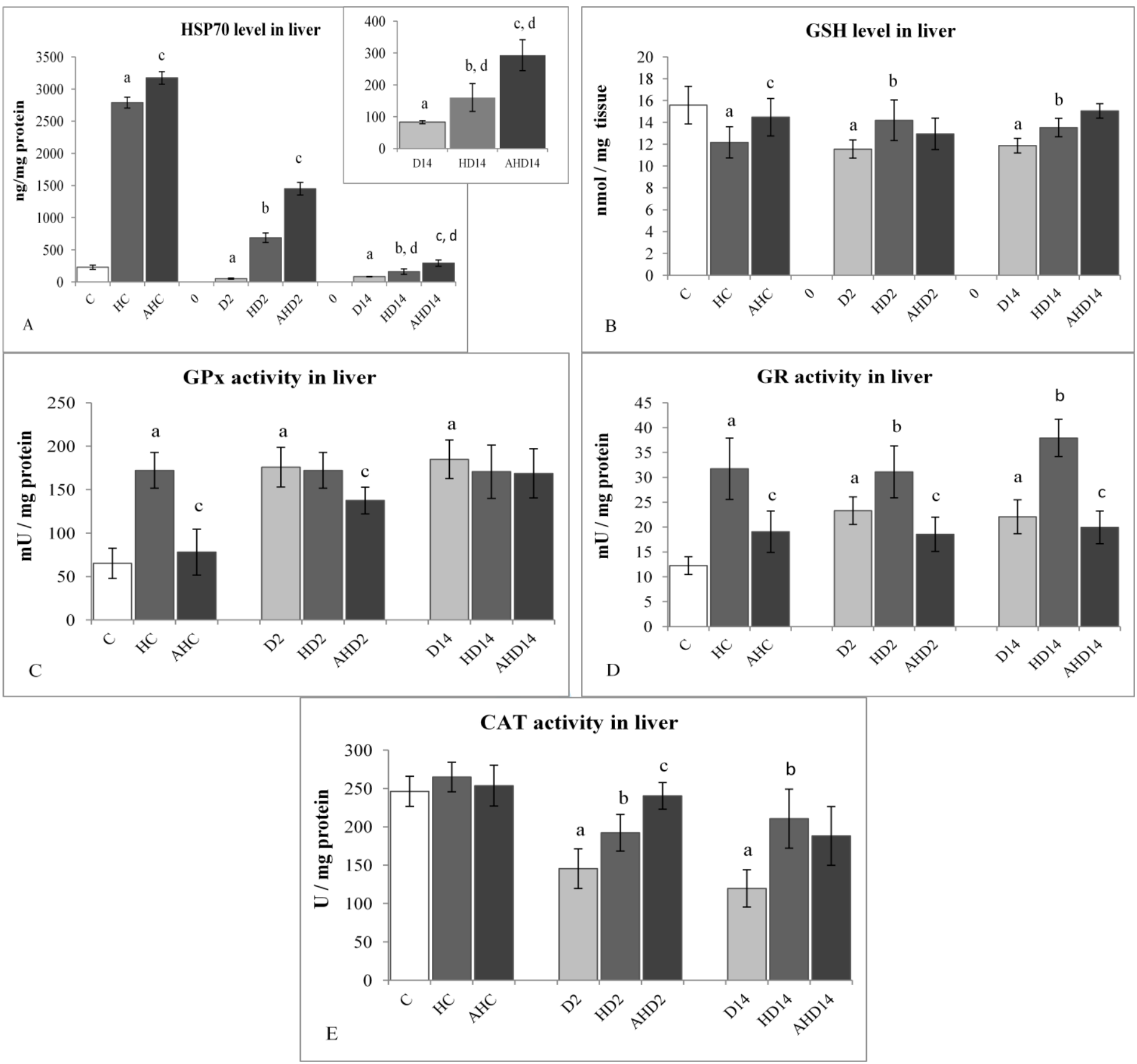